\title{
A new method for giving voting advice: How researchers can turn voter "Hmm's" into HMMs (hidden Markov models)
}

\section{Marilena Agathokleous \\ Nicolas Tsapatsoulis}

\section{Video Abstract}

Keywords: Hidden Markov Models, Voting Advice Applications, collaborative filtering, expectation maximisation, recommender systems

Posted Date: November 21st, 2020

DOl: https://doi.org/10.21203/rs.3.rs-113098/v1

License: (c) (i) This work is licensed under a Creative Commons Attribution 4.0 International License. Read Full License 


\section{Abstract}

Indecision is quickly becoming a thing of the past. Whether it's content, cuisine, or companionship we crave, technology seems to know just what to serve up. But what about life's bigger decisions? The ones that probably should give us pause? A recent study suggests that there might soon be an app for those too, namely for voting. Using machine learning, researchers from Cyprus have developed a way to predict the political party that best chimes with a voter's values. And while not the first algorithm designed to counsel voters, it could be the best one out there. From a data science perspective, teaching computers to dole out voting advice is no different than getting social media apps to guess your next favorite show or soul mate. The trick is finding patterns in user choices. Not just your own-those of every user like you. In the context of voting, that means finding voters who share your stance on the same issues. To do this, the research team applied a machine learning technique called hidden Markov modeling. Given enough data about seemingly unrelated events, a hidden Markov model can venture a good guess about what should happen next. The researchers trained their models to spot patterns among thousands of responses to a survey on foreign and domestic policy issues. The idea was that voters with similar response patterns would likely vote for the same political party. The researchers tested their models using survey data from three different countries: Cyprus, Greece, and Germany. In each case, they "covered up" the answer to the one survey question that asked voters to identify with a political party. They then compared their models' guess with the voters' response. Overall, the models largely outperformed other methods for predicting party allegiance, especially for voters from Germany and Cyprus-which is revealing. Because although they didn't produce the biggest datasets, Germany and Cyprus did show better-defined voter response patterns. That suggests that data quality rather than quantity might be the key to making good predictions. This new approach to voter recommendation could help clear the air for large swaths of voting populations, such as undecided or first-time voters. That could be a big win for democracy and usher in a new era of personal decision making. 